\title{
Prevention from a community perspective facilitating and constraining factors perceived by nurses in local community health centers in the course of prevention and health promotion
}

\author{
Bregje D'haeze ${ }^{1}$, Wim Peersman ${ }^{2}$, Ann Van Hecke ${ }^{1,3,4}$, Ignaas Devisch $^{5^{*}}$ \\ ${ }^{1}$ Department of Nursing Sciences, Ghent University, Ghent, Belgium \\ ${ }^{2}$ Department of Primary Care, Ghent University, Ghent, Belgium \\ ${ }^{3}$ Department of Public Health, Faculty of Medicine and Health Sciences, Ghent University, Ghent, Belgium \\ ${ }^{4}$ University Hospital Ghent, Ghent, Belgium \\ ${ }^{5}$ Department of Physical Therapy and Rehabilitation Sciences, Ghent University and Artevelde University College, Ghent, Belgium \\ ${ }^{*}$ Corresponding Author: Ignaas.Devisch@UGent.be, ignaasdevisch@scarlet.be
}

Received 14 August 2012; revised 13 September 2012; accepted 20 October 2012

\begin{abstract}
The purpose of this paper is to explore the stimulating factors and the obstacles experienced by nurses in community health centres in their work with prevention and health promotion. We conducted the qualitative research design consisting of fifteen nurses in five community health centres in Ghent. There was also a focus group and participant observation. All participants experienced stimulating factors as well as obstacles in their work with preventive interventions. The most strongly facilitators were the Electronic Medical File and the multidisciplinary approach. The obstacles mentioned by the nurses were the communication problems and the financial problems. This study may have an important impact on nursing practice and nursing prevention. Further research is needed on nurses working in community health centres and the way they approach their patients in the course of preventive actions.
\end{abstract}

Keywords: Nursing; Community; Obstacles; Stimulating Factors; Preventive Health Care

\section{INTRODUCTION}

All over the world, there is a lot of interest for prevention. As is well known, in 2005, the World Health Organization [WHO] identified three different types of prevention [1]: primary secondary and tertiary prevention. From these three types, we can recognize that prevention is also a very important task in community health care, especially for nurses. Nurses are profoundly in- volved in prevention. Consequently, it is very important to acknowledge the consequences both for the patient sand for the nurses' own professional development. However, little is found in scientific literature about this topic.

Although there is lack of literature about nursing activities in preventive care, earlier research [2] concluded that there are many factors that influence the preventive activities of nurses. These factors may or may not be facilitating. According to some authors, the lack of motivation by patients could be a challenge for nurses in giving preventative care. Another major barrier for nurses is communication with patients due to cultural or language differences [2].

The community health centre is an extramural setting where prevention and health promotion is common. Two central activities of this setting are prevention and health promotion and high quality health care [3].

Recently, community health centres became to have a more important role. They were upgraded due to government projects and the great efforts of the community health centres and their nurses [3]. The past years it's been easier to consult community health centres. One of the reasons is the accessibility of these centres: the patient doesn't have to pay right away to consult a doctor or nurse. Due to the economic situation, the community health centres are a benefit for the patient as well as the society. The Belgian health insurance (RIZIV) pays a monthly amount to the centres. This amount depends on the number of patients that were treated. The patient can consult a community health centre free of charge; however when the patient wants to consult another doctor, he will be charged the regular amount.

In 2010, there were more than 250,000 patients in Belgian community health centres, this is twice the amount 
in comparison with seven years ago. As a consequence, the amount of centres in Belgium has grown in the last years: from 51 in 2002 to 110 in 2010.

A community health centre takes care of the individual and groups disease prevention. One of its most important objectives is to strengthen and to promote the self-activation of the patients, therefore the community health centres strive for proactive working [4].

Multidisciplinary cooperation is very important for a community health centre. They claim to let all disciplines cooperate. In most community health centres, the patients consult doctors, nurses, occupational and physical therapists that form a team. Some centres have also a dentist, a social worker and even a psychologist. This multidisciplinarity promotes continuity in health and nursing care and facilitates preventive care [3].

Wilhelmsson \& Lindberg [5] emphasise how important it is that the multidisciplinary team in a community health centre shares the objectives and priorities of the necessary structure. While each discipline keeps its own function, cooperation is useful in all situations. Moreover, structure plays a large role in sharing the know-how and the experience of (nursing) practice.

\section{STUDY OBJECTIVE}

The aim of this study is to explore and describe both the most strongly stimulating factors and the obstacles experienced by nurses of a community health centre in their work with preventative care.

\section{METHODOLOGY}

The present study has a qualitative design, and is meant to be prospective. Facilitators and barriers are identified by focus group and participant observation. The software program QSR N6 was used to analyse the data. In this program, all data are categorised by subject. Later, different subjects with the data are linked in order to create the required structure.

\subsection{Setting and Participants}

All five community health centres in Ghent, Belgium, were asked to participate. A letter and e-mail were sent to their nurses describing the aim of the study. Later on, more information was given by telephone and they were invited to receive face-to-face information. All community health centres agreed to participate.

Criteria for participating in the study were speaking Dutch and working as a nurse in one of the five community health centres in Ghent. Fifteen out of the eighteen nurses participated in the study. The nurses were aged between 21 and 60. Three men and twelve women participated (see Table 1).

\subsection{Focus Group}

One focus group was held in each community health centre. Focus groups are a responsible choice in a qualitative design because of their open questioning and because they give the participants many opportunities for discussion [6]. In addition, a focus group makes it easier to get to know something about the experiences of the nurses. There is interaction and all the nurses can react immediately.

\subsection{Participant Observation}

To gather more information, we used participant observation in one of the five community health centres. The researcher observed the nurses' work over 80 hours and participated in nursing interventions, multidisciplinary health promoting activities and organised home visits. With this form of data gathering, there were more opportunities for the researcher to form a picture of the real situation experienced by nurses in the community health centre.

\subsection{Ethical Considerations}

The study was conducted with the ethical approval of the University of Ghent. The rights of the participants were protected by maintaining the ethical standards as stipulated by the Ethics Committee of the Ghent University. Written and verbal information was given in a consent form, which included information about the study.

\subsection{Data Analysis}

The focus group was recorded on audio- and videotape. All nurses gave their consent. The videotape was used to check what the nurses said and to observe the reactions of the nurses during some discussions. Subsequently, an open-coding method was used that followed the QSR N6-program. After collecting the data from one focus group, the researcher read the report and identified ideas and topics. Finally, an interview guide of the most important stimulating factors and obstacles was developed.

The data from the participating observation was gathered during the 80-hour period. Notes were taken and a daily report was made of the nursing activities and the observed reactions and interventions. These daily reports were also coded in QSR N6 with the help of the codes used for the analysis of the focus group. This meant that

Table 1. Sex and experience of the nurses in the community health centre.

\begin{tabular}{cccccc}
\hline & \multicolumn{3}{c}{ Sex } & \multicolumn{3}{c}{ Experience in Years } \\
\cline { 2 - 6 } & $\mathrm{M}$ & $\mathrm{F}$ & $\leq 5$ & $6-10$ & $11-15$ \\
\hline Nurses & 3 & 12 & 9 & 3 & 3 \\
\hline
\end{tabular}


the participant observation data could be checked with that from the focus group.

\section{RESULTS}

Nurses working in community health centres reported in this study stimulating factors as well as obstacles in their work with preventative care to their patients. According to earlier research $[7,8]$, the stimulating items identified during the research were divided into three categories: features of the organization, features of the nurse and features of the patient. The obstacles experienced were also divided into two categories: features of the nurse and the organisation and features of the patient. The stimulating factors as well as the obstacles are shown in Figure 1.

\subsection{Stimulating Factors}

\subsubsection{Features of the Organization}

\section{1) Multidisciplinary Work}

This cooperation promotes the preventive character of the community health centre. Nearly all the nurses agreed with this topic and it was the most strongly stimulating factor for prevention.

Because the nurses see the patient almost every day, they also have a referring function. If they notice some problems, they can refer their patient to a colleague in the community health centre. For instance, a new diabetes patient will be referred to a dietician. The nurses noticed that it is important that they can still follow their patient after the referral. The Electronic Medical File can encourage this.

Nurse 2A: Yes, and it's also very good if you can convince a patient. Sometimes, if a patient doesn't want to listen to our advice, I have the confidence to say that the whole team supports this advice or the guideline. Or sometimes, the patient only wants to listen to the advice of the doctor and then I can say that the advice comes from the doctor. In fact, this is multidisciplinary working!

\section{2) The Electronic Medical File}

Some nurses found the Electronic Medical File a stimulating factor in prevention. They described the Electronical Medical File as a praxis-oriented item for following the history of each patient. Following the medical history concerning vaccinations, etc can help nurses to encourage the patients to take part in preventive care, mammography or influenza vaccination.

\section{3) Perspective}

Almost sixty percent of the nurses experienced the perspective of the community health centre as a stimulating factor. This perspective consists of a proactive principle and curative care. Nearly all nurses identified the perspective as part of their daily work. They have a lot of suggestions for prevention during their daily work.
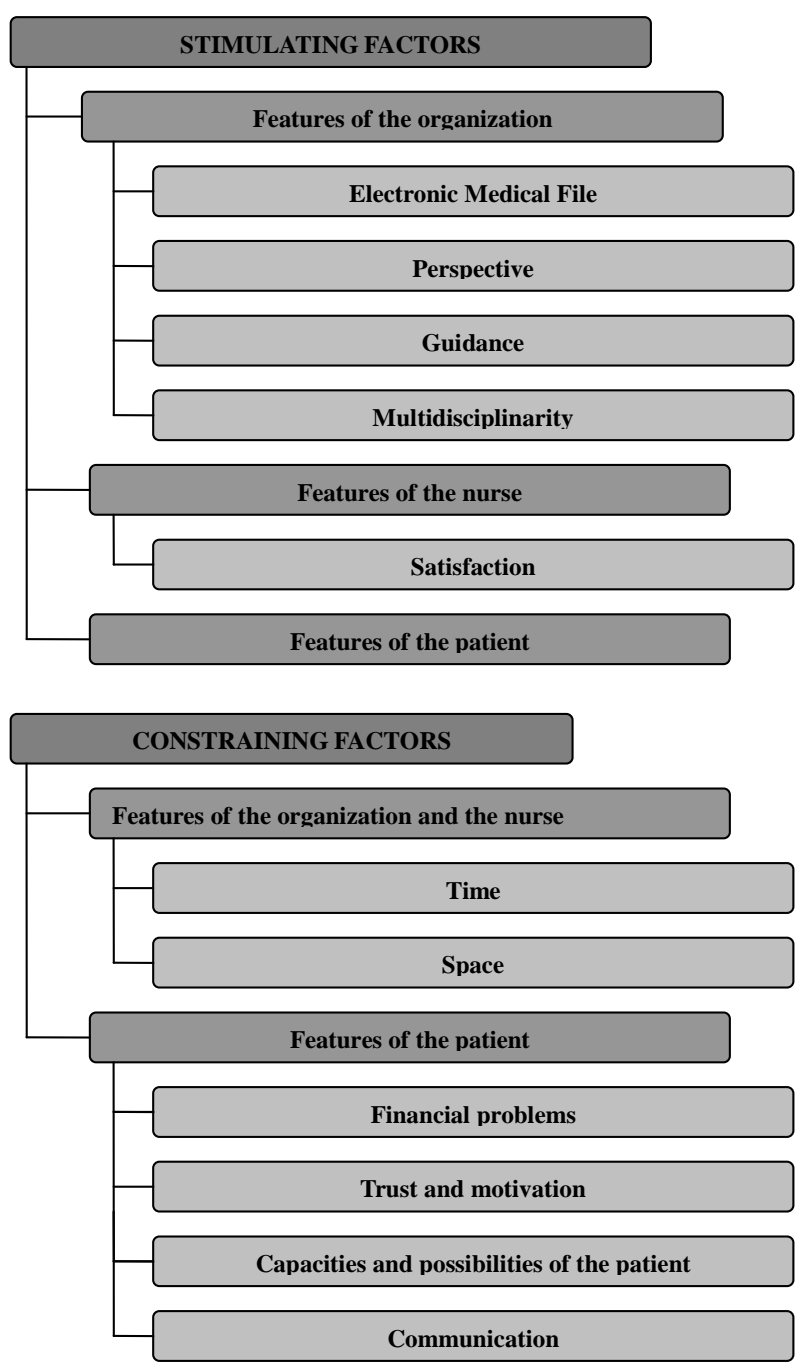

Figure 1. Stimulating and constraining factors experienced by the participants.

Moreover, the nurses paid attention to the needs of the people in the community centre. An example:

Nurse 3B: A lot of attention is given to the community: what are the needs of the people? And, if possible, we try to do something about it. We have to spend time on these things. And I think that is a very important thing for the community health centre to offer.

4) Guidance and Coaching

The guidance has to be adequate in the community health centre. In some community health centres, one person is particularly involved in prevention and health promotion. This person creates, organises prevention and promotes projects. Nurses are involved in these projects and they can stimulate the patients to participate. It is possible that nurses see a problem with patients and discuss it with social workers or health promotion workers.

Nurse 5A: Yes, I think if we see something in our daily practice, like there was a period that there were a lot of 
burning accidents at home. Then I went to the health promotion worker to talk about it and we created a big project to prevent these accidents.

\subsubsection{Features of the Nurses}

\section{Satisfaction}

Nurses giving preventative care will be more motivated if their interventions are successful. If patients follow the given guidelines and advice, the nurses feel stimulated to do more. Sometimes, it takes a quite long time before patients do something with the prevention advice, but the nurses are still very satisfied when they see the consequences.

Nurse 1B: I think that when I see the results-for instance, when I see that a lot of patients went to the doctor for a mammography or something like that-then I'm thinking "Yes, that's good! The advice that I gave was good for the patient and she listened!"

\subsubsection{Features of the Patients}

Several patients in the community health centre have a poor lifestyle, which is a big risk for their health. More than half of the nurses said that it is important to detect the problems and the needs in this group. Not only the medical needs, but also social and psychological problems must be explored. In this light, the relation between the patient and the nurse is important.

A few nurses also remarked that it is a good thought to organise a home visit with some patients.

Nurse 4A: You can see and detect most of the patients' problems in their own homes!

But, on the other hand, home visits can sometimes be an obstacle because the patient is reluctant and will decide themselves what to do in their own place.

\subsection{Constraining Factors}

\subsubsection{Features of the Nurses and the Organization}

Time and Physical Space

Although the nurses experienced perspective and time as stimulating factors, they also see time as an obstacle. They also have an important curative task and they don't have so much time to give as much prevention as they would like.

Nurse 1B: Well, an obstacle is also, yes... time! We want it, and we would like to give prevention but... how can I say this... yes, there are only 24 hours in a day and we have some things that we have to do, so prevention is not always so easy to give!

All nurses in two community health centres talked about a lack of a space. They would like to give prevention in an empty room, on a quiet moment, without other people. In fact, they were thinking of a special "prevention" room: a personalized room to be used only for pre- ventive activities.

\subsubsection{Features of the Patients}

\section{1) Financial Problems}

Even if easy access exists to the community health centre, it's still difficult for some patients to follow the advice given by the nurses. Because they have to live with a small amount of money (for instance, the fifty Euros they can get every week) and therefore need to make hard choices. Often they choose food and drinks or other necessities, so they won't have some money to pay for a medical examination or preventive activity.

Nurse 1A: Some patients are worrying a lot and their most important concern is to keep away from bailiffs, to pay the creditors and accounts. Money for medicine and health measures, even though they have diabetes or other diseases, is not one of their prime concerns.

2) Trust and Motivation

Nearly all nurses talked about the lack of motivation and trust of the patients. They don't trust nurses or are not motivated to change their behaviour or to accept advice. In fact, the nurses said that changing behaviour is not easy and they cannot achieve it on the short run. Some patients don't pay attention to prevention and, in any case, it is very hard to convince them.

A few nurses blamed the poorer population and the immigrants but most denied this.

Nurse 4A: Yes, some patients don't keep consultations they made. If I have an appointment and I can't be there, I will give a call. But, yeah, not all the people have this idea (laughing)...

Finally, the nurses said that it's still very hard to change something that you are used to do. A patient who is overweight or who has obesity will be advised to eat healthily and to do some sport. But if this patient never did it before, it will be very difficult to start with!

3) Patients' Capacities and Their Options

More than half of the nurses said that patients really couldn't follow their advice. They don't have the capacity to do it themselves and don't know people who can help them.

Nurse 3B: In some people, yes, I don't know how to say it, but some patients are not... bright! And then, it's very hard to explain what we want them to do. For instance, they can't read the labels on the food products.

4) Communication

One of the biggest obstacles, carried out by all par- ticipating nurses, is communication. Non Dutch-speaking patients are very hard to work with. Sometimes, the community health centres work with interpreters or patients bring a relative or family member of the patient will translate, but this is not always reliable. All the nurses confirmed that language is a very important matter in preventative care. The nurses use the repeating 
technique to check that their patient understood the advice or the guidelines.

Nurse 2B: (...) The patients often shake their head and agree if we say something; but if we ask them to repeat what we would like to achieve, they just can't...

Next to the language problems, there is also a problem of culture. Some people have different eating habits or have different ideas about therapy. The Ramadan period is one the classic examples of this problem.

\section{DISCUSSION}

The results of this study show that nurses experience stimulating factors as well as obstacles in the course of preventative care in community health. These results can be interpreted in a praxis-oriented way. Nurses working in community health care can learn from the results of this study and can use the information and the outcomes in their own practice. For instance, they may take into account the bad financial situation of the patients. The perspective of the community health centre and the multidisciplinary work were the strongest stimulating factors, while financial problems and communication problems presented the greatest obstacles.

There is a lack of research on the experiences of nurses giving preventative care in community health. Therefore, it isn't easy to compare the results of this study with the results found in the specialist literature. Consequently, we have found few similarities. Nevertheless, this study can be a stimulus for nursing practice and for community health in general.

\subsection{Stimulating Factors}

In this study the nurses experienced the Electronic Medical File as one of the stimulating factors. This has been confirmed by Winters et al. [2]. They concluded that it is a good instrument for following the medical history of the patient and for seeking continuity of care.

A second stimulating factor for the participating nurses identified in the focus groups as well as in the participant observation was multidisciplinary cooperation. This was identified as the largest stimulating factor in community health. All disciplines can support each other in making decisions. Ferrari \& Rideout [9] showed in their study that nurses are experts in cooperating with different disciplines. Additionally, Doyle [10] stipulated multidisciplinary work as a major stimulus in community health. She said that there is a lot of cooperation for reaching an overall view of complicated situations. Nevertheless, Doyle [10] also said that time and communication are necessary to form a holistic multidisciplinary team. However, these factors are found in some literature and in the present study to be obstacles.

On the other hand, Poulton and Winters et al. [2,7] de- scribed a lack of professional relations and a lack of cooperation in health care between the different disciplines.

Furthermore, Wilhelmsson \& Lindberg [5] found the perspective in the community health centre to be a stimulating factor for giving preventative care, but also said that there is a need for time, supervision and motivation to become a good environment. They also stipulated that nurses have to be motivated and satisfied in what they are doing. If this can be achieved, the nurses' attitude can help them in convincing the patient to follow their advice.

\subsection{Obstacles}

In the present study, we identified some obstacles encountered by the nurses in the community health centre in their work with preventative care. The nurses in this study experienced a lack of guidance as an obstacle. In the literature, Azwihangwisi, Vhonani \& Mashudu and Winters et al. [2,11] identified the lack of material and personnel as a major obstacle. There are too few working people, too few nurses and not enough space to work. As a consequence, there will be a risk that prevention will fall back into being a back-up plan.

In the same study by Azwihangwisi, Vhonani \& Mashudu [11], a lack of time was identified, but they said that this factor has to be explored. Most of the nurses in their study, and also in the present study, gave priority to curative care and also gave preventative care because they were convinced of its importance. So, as a consequence, preventive care isn't integrated into nursing care yet. For instance, patients with a high degree of physical dependence do not always have the time to follow some advice or even to get advice. In addition, Eddy, Kilburn, Chang, Bullock \& Sharp and Wilhelmsson \& Lindberg [12] identified time as a great obstacle.

Eddy, et al. and Wilhelmsson et al. [5,12] said that nurses are too busy with administrative work and that this is a major reason why they sometimes cannot implement the prevention strategy. This did not appear at all during our research-neither in the focus group nor in the participant observation.

Plews [13] identified a lack of knowledge amongst the nurses in community health. Again, this factor was not proven at all by the present study. This may be due to the questioning, because only a few nurses identified some factors arising from themselves as an obstacle or stimulating factor in the course of prevention in a community health centre.

A few authors discovered obstacles due to the patient. In this study, we identified many obstacles due to the patient. Lasser, Ayanian, Fletcher, Del Vecchio \& Good [14] explore patient-related obstacles in their study. They said patients don't trust enough the nurses and commu- 
nity health services. This can make it hard to give good prevention. To make the relationship between nurse and patient more trustworthy, one-by-one consultations can be helpful. If patients can always consult the same nurse or at least two different nurses, they are able to develop a good professional relationship.

Some of these obstacles can be overcome by the nurses. For instance, in language problems, the nurses can show pictures to the patient to explain their activities. Home visits can be made more comfortable for the nurse and the patients when a family member is present.

\section{LIMITATIONS}

The present study was performed with some limitations. First, we found a lack of literature. Secondly, there were a few limitations in the qualitative design and in the focus group. Five community health centres participated. In two of them, only two nurses were appointed, but we have chosen to continue with them. Furthermore, the five community health centres are different in certain points. There was a community health centre that has existed for more than ten years and another that had existed for just a few years. As a possible consequence of this, the more recent community health centre could not reach the same level of prevention, but we saw that they are making great efforts to achieve it.

Moreover, the focus group took place in an environment that is well known to the nurses, namely their own community health centre. All participants in one focus group knew each other because they were colleagues. One of the drawbacks of this situation is a lack of discussion between the participants, precisely because the community health centre has the same stimulating factors and obstacles.

Third, this study only looked at preventive intervenetions and how they worked. It was important to explore the stimulating factors and the obstacles involved in giving preventative care, but no great attention was paid to correlation or interaction between the stimulating factors and the obstacles.

A big benefit of focus group is the possibility to explore experience. But, on the other hand, it can be difficult for some people to talk about complicated issues in a group. In an effort to overcome this, there was always one focus group in one community health centre. The nurses know each other and this gave more opportunities for discussion.

Despite these limitations, a few factors show the value of this study. In the present study data triangulation was used, which is good for internal validity. The reliability and the ability to check and monitor are better because the focus group was recorded twice [8]. Also, the fact that each focus group and the participant observation have been written by hand enhances the validity. All participants have been made anonymous and all the focus groups took place in an empty and quiet room in their own community health centre.

Nevertheless, the results of the present study may be favourable for the nursing practice. Some factorsstimulating as well as hindering - were found in all the community health centres. On the other hand, some factors were found in only one centre. In one of the health centres, the nurses identified adapted physical space as an obstacle. This wasn't mentioned in the other centres. Two of the five participating community health centres were renovated in recent years, so they had better infrastructure for the patients. It is possible that a factor only occurs in one centre and is not recognised as a stimulating factor until later. One such factor is time. By reading the results, some community health centres can learn from each other.

\section{Further Research}

This study was meant to be prospective. But more research about nursing and preventive health care has to be done. Despite the lack of literature, there is a need for further research in this area. Further research may consist of exploring more stimulating factors and obstacles experienced by nurses working in community health centres. This can be done with a larger sample, which might be all Flemish community health centres. There is also a possibility to explore relationships and correlations between stimulating factors and obstacles and giving prevention-is a lack of prevention a consequence of communication difficulties between the patient and the nurse?

\section{CONCLUSIONS}

The aim of this study was to identify the stimulating factors and the obstacles experienced by nurses working in community health in the course of preventative care. Nurses experience stimulating as well as hampering factors in their work with preventative care. Multidisciplinary teamwork, the Electronic Medical File, the perspective in the community health centre and guidance were the most important stimulating factors. As a consequence, nurses will be motivated to, and find satisfaction in, giving preventative care if patients follow their advice.

Time has been identified as a double factor: stimulating because the perspective in the community health centre gives them enough time, but as an obstacle because there are also curative interventions. Furthermore, the financial aspect, the trust and motivation from the patient, the capacities of the patients and communication problems are identified as obstacles for giving preventative care in a community health centre. Time and multidisciplinary teamwork were also researched in existing 
professional literature.

\section{REFERENCES}

[1] WHO (2005) The Bangkok charter for health promotion in a globalized world. http://www.who.int/healthpromotion/conferences/6ghcp/b angkok_charter/en/

[2] Winters, L., Gordon, U. Atherton, J. and Scott-Samuel, A. (2007) Developing public health nursing: Barriers perceived by community nurses. Public Health, 121, 623633. doi:10.1016/j.puhe.2006.12.012

[3] Verweij, A. (2006) Preventie in de wijk. Doelen en methoden. Wat wordt er met de preventie in de wijk beoogd? http://www.rivm.nl/vtv/object_document/o3086n33078.ht $\underline{\mathrm{ml}}$

[4] Passchyn, L. (2008) Concept wijkgezondheidscentrum. http://www.vwgc.be/index.php? module=pagemaster\&PA GE user op=view page\&PAGE $\mathrm{id}=82 \& \mathrm{MMN}$ position $=1 \overline{64}: 16 \overline{4}$

[5] Wilhelmsson, S. and Lindberg, M. (2009) Health promotion: Facilitators and barriers perceived by district nurses. International Journal of Nursing Practice, 15, 156-163. doi:10.1111/j.1440-172X.2009.01740.x

[6] Grypdonck, M. (2008) Bijzondere topics in nursing \& midwifery. Integrerende verpleegkunde als verpleegsysteem. Onuitgegeven Cursusmateriaal, Universiteit Gent.

[7] Poulton, B. (2009) Barriers and facilitators to the achievement of community-focused public health nursing practice: A UK perspective. Journal of Nursing Management, 17, 74-83.
[8] Plews, C., Billingham, K. and Rowe, A. (2000) Public health nursing - barriers and opportunities Public health nursing - barriers and opportunities [Electronical version]. Health and Social Care in the Community, 8, 138-146.

[9] Ferrari, A. and Rideout, B. (2005) The collaboration of public health nurses and primary care nurses in the development of a nursing managed health centre. Nursing Clinics of North America, 40, 771-778. doi:10.1016/j.cnur.2005.08.006

[10] Doyle, J. (2008) Barriers and facilitators of multidisciplinary team working: A review. Pediatric Nursing, 20, 2629.

[11] Azwihangwisi, H.M.-M., Vhonani, O.N. and Mashudu, D.-M. (2007) Nurses' experiences of delivering voluntary counselling and testing services for people with HIV/ AIDS in the Vhembe District, Limpopo Province, South Africa. Nursing and Health Sciences, 9, 254-262. doi:10.1111/j.1442-2018.2007.00341.x

[12] Eddy, T., Kilburn, E., Chang, C., Bullock, L. and Sharps, P. (2008) Facilitators and barriers for implementing home visit interventions to address intimate partner violence: Town and gown partnerships. Nursing Clinics of North America, 43, 419-435. doi:10.1016/j.cnur.2008.04.005

[13] Lasser, K.E., Ayanian, J.Z., Fletcher, R.H. and DelVecchio Good, M.-J. (2008) Barriers to colorectal cancer screening in community health centers: A qualitative study. BMC Family Practice, 9, 15-24. doi:10.1186/1471-2296-9-15

[14] Maso, I. and Smaling, A. (1998) Kwalitatief onderzoek: Praktijk en theorie. Uitgeverij Boom, Amsterdam. 